\title{
Young Adults' Attachment Orientations and Psychological Health Across Cultures: The Moderating Role of Individualism and Collectivism
}

\author{
Hong-hui Lin,' Pony Yuen-Ga Chew ${ }^{2}$ and Ross B. Wilkinson ${ }^{3}$ \\ 'Australian National University, Canberra, Australian Capital Territory, Australia \\ ${ }^{2}$ Centre for Evidence and Implementation, Melbourne, Victoria, Australia \\ ${ }^{3}$ University of Newcastle, Newcastle, New South Wales, Australia
}

\begin{abstract}
Claims that adult attachment differences across cultures are associated with individual differences in individualism and collectivism have seldom been evaluated. This study investigates how individualism and collectivism may relate to adult attachment orientations (anxiety and avoidance) and whether they moderate the attachment-psychological health link. In samples of young adults from Western (Australians, $n=143$ ) and Eastern (Singaporeans, $n=146$ ) locations, individual differences in individualism and collectivism were significantly associated with attachment avoidance but not anxiety. As predicted, attachment anxiety predicted worse negative symptoms more strongly among individuals higher in collectivism across cultures. However, individualism and collectivism did not moderate the relation between avoidance and negative symptoms. Results suggest there are other factors leading to the differential moderating effect of individualism and collectivism in the attachment-wellbeing link across cultures. The current study highlights the need to look beyond cultural stereotypes in clinical practice.
\end{abstract}

- Keywords: attachment, culture, individualism, collectivism, psychological health

Close relationships profoundly influence our development and adjustment, and less than optimal relationship functioning (e.g., break-up, divorce, loneliness) is associated with serious consequences for health and psychological wellbeing (Perissinotto, Stijacic Cenzer, \& Covinsky, 2012; Prigerson, Maciejewski, \& Rosenheck, 1999; Sbarra \& Emery, 2005). Attachment theory has been used to examine the nature of healthy and unhealthy adult close relationships, their hypothesised precursors, and consequences for functioning; and, more recently, cultural similarities and differences (Fraley \& Davis, 1997; Hazan \& Shaver, 1987; Mikulincer \& Shaver, 2007; van Ijzendoorn \& Sagi-Schwartz, 2008). Emerging cross-cultural comparison studies have found notable differences in adult attachment patterns, and these are often assumed to be linked to cultural differences in individualism and collectivism orientations (e.g., Friedman et al., 2010; Lu, Zhang, Michael, \& Chan, 2009; Mak, Bond, Simpson, \& Rholes, 2010; Malley-Morrison, You, $\&$ Mills, 2000). However, available studies have yet to demonstrate conclusively whether, and how, individualism and collectivism associate with attachment representations as they rarely empirically examine the assumptions around these constructs. The current study seeks to address this gap in the literature by systematically examining the relations between attachment expectancies and cultural orientations across samples of late adolescents/young adults from Western (Australian) and Asian (Singaporean) cultures of origin.

\section{Adult Attachment in Westerners and East Asians}

Individual differences in adult attachment styles develop from early experiences of intimate relationships and are argued to be defined by two dimensions: anxiety (over separation, abandonment, or insufficient love)

\footnotetext{
ADDRESS FOR CORRESPONDENCE: Ross B. Wilkinson, School of Psychology, University of Newcastle, Callaghan NSW 2308,
} Australia. Email: Ross.Wilkinson@newcastle.edu.au 
and avoidance (of intimacy, dependency, and emotional expressiveness; Brennan, Clark, \& Shaver, 1998; Mikulincer \& Shaver, 2007). Attachment anxiety and avoidance vary across individuals, with low scores on these two dimensions interpreted as attachment security and high scores as attachment insecurity (Bartholomew \& Horowitz, 1991; Mikulincer \& Shaver, 2007). Attachment theorists argue that the negative expectancies of relationships represented by insecure attachment frustrate the fulfillment of the human need for security, leading to emotional distress and relationship difficulties (Hazan \& Shaver, 1994; Wilkinson, 2010; Wilkinson \& Scherl, 2006). Research, predominantly conducted on White, Western populations, shows that attachment anxiety is associated with symptoms of depression, anxiety, and social difficulties, whereas attachment avoidance is more commonly restricted to associations with social difficulties (Bartholomew \& Horowitz, 1991; Horowitz, Rosenberg, \& Bartholomew, 1993; Kim, Carver, Deci, \& Kasser, 2008).

East Asian populations (e.g., Chinese from Hong Kong and China, international students of Chinese ethnicity) form a significant proportion of non-Western, nonWhite samples in cross-cultural studies of adult attachment. In these mostly single, cross-group comparisons, these participants typically show significantly higher attachment anxiety and avoidance than their Western, Caucasian counterparts who are predominantly North Americans (e.g., Cheng \& Kwan, 2008; Friedman et al., 2010; Ho et al., 2010; Lu et al., 2009). However, attachment anxiety and avoidance have been found to predict poorer outcomes in both Western and East Asian (including Asian American) samples alike. Attachment anxiety has been associated with more psychological distress as well as poorer relationship outcomes, such as less perceived social support, lower relationship satisfaction, and more interpersonal conflict (Friedman, 2006; Friedman et al., 2010; Mak et al., 2010; Wei, Russell, Mallinckrodt, \& Zakalik, 2004). Avoidance has more often been associated with poorer relationship outcomes in romantic relationships (Friedman, 2006; Friedman et al., 2010; Ho et al., 2012; Ho et al., 2010) but not consistently with poorer psychological health (e.g., Friedman, 2006; Mak et al., 2010; Wei et al., 2004).

While some authors have argued that the relationship between attachment and psychological functioning is invariant across Western and East Asian samples (e.g., Ditommaso, Brannen, \& Burgess, 2005; Ho et al., 2012; You \& Malley-Morrison, 2000), a number of studies have found stronger associations between attachment orientations and psychosocial outcomes in East Asian than Western samples (Friedman, 2006; Mak et al., 2010; Wei et al., 2004). Wei et al. (2004) found that Asian Americans showed a stronger positive association between attachment anxiety and negative mood than Caucasian Americans. Friedman (2006) found that attachment anxiety, avoidance, and self-construals all predicted relationship and mental health outcomes across three cultures: Hong Kong, Mexico, and the United States. While avoidance showed equally strong association with depressive symptoms across cultures, its associations with relationship outcomes were stronger in Hong Kong and Mexico than the United States. These findings suggest that culture might moderate the influence of attachment representations on psychosocial outcomes.

\section{Individualism, Collectivism, and Adult Attachment}

The individualism-collectivism framework ${ }^{1}$ is the dominant approach in the literature to characterise and explain many cross-cultural differences across various psychological domains such as attribution styles, wellbeing, selfconcept, and relationality (Oyserman, Coon, \& Kemmelmeier, 2002), as well as adult attachment (e.g., Friedman et al., 2010; Malley-Morrison et al., 2000). While individualism and collectivism have more commonly been treated as polar opposites of a single dimension at the culture level (e.g., Hofstede, 1980; Hui, 1988), there is accumulating research to support conceptualising them as two separate dimensions at the individual level (e.g., Oyserman et al., 2002; Triandis \& Gelfand, 1998).

In the attachment literature, individualism and collectivism have sometimes been referred to as independentinterdependent self-construals (Wang \& Mallinckrodt, 2006; Wang \& Ratanasiripong, 2010). Exposure to individualist or collectivist cultural norms is thought to promote the relative development of independent and interdependent self-construals respectively (Markus \& Kitayama, 1991). Individualism is characterised by a view of the self as discrete and separate from others, an emphasis on independence, self-reliance, personal identity, and unique qualities about the self, and is most often associated with Western industrialised, White middleclass populations (Markus \& Kitayama, 1991; Oyserman et al., 2002; Singelis et al., 1995). Collectivism is characterised by a view of the self as interconnected with others and embedded in relational networks, a duty to the in-group, and an emphasis on social harmony, and is most often associated with Eastern or Asian populations (Markus \& Kitayama, 1991; Oyserman et al., 2002; Singelis et al., 1995).

This general understanding of the individualismcollectivism distinction forms the most typical account for East-West differences in adult attachment patterns (e.g., Friedman, 2006; Mak et al., 2010; Lu et al., 2009; Malley-Morrison \& You, 2000; Wei et al., 2004). This is perhaps because attachment orientations and individualism-collectivism are considered to be 'fundamentally concerned with predictable patterns in relationships between self and others' (Wang \& Mallinckrodt, 2006, p. 194). Relationships do not occur in a cultural vacuum, and it is reasonable to expect that attachment 
patterns would be associated with varying levels of individualism and collectivism thought to entail different cultural expectations, beliefs and values about relationships (Wang \& Mallinckrodt, 2006).

Attachment researchers have suggested that the stronger collectivistic orientation attributed to East Asians/Chinese contributes to their higher need for social approval and greater sensitivity to social influence, which are putatively associated with their higher attachment anxiety relative to Westerners (e.g., Cheng \& Kwan, 2008; Wang \& Mallinckrodt, 2006). Others have suggested that East Asians' higher attachment anxiety may be linked to their strong family orientation and the high value placed on maintaining close, lifelong relationships with parents (Wang \& Mallinckrodt, 2006; Wei et al., 2004). On the other hand, researchers have argued that East Asians' higher attachment avoidance may be rooted in their collectivistic values and norms (social harmony and reciprocity) that promote preferences for restrained emotional/verbal expression and greater interpersonal distance to minimise the high costs of reciprocal social support (Cheng \& Kwan, 2008; Taylor, Sherman, Kim, Jarcho, Takagi, \& Dunagan, 2004; Wei et al., 2004). Other perspectives suggest that East Asian/Chinese populations' insecure attachment might be more strongly associated with negative, psychosocial outcomes than Westerners' because: (1) relationships are more integral to their self-definition, source of self-esteem, and happiness, which may likely cause more distress when they are not functioning well; and (2) insecure attachment orientations, such as high attachment avoidance, are at odds with collectivistic/interdependent cultural norms, resulting in poor person-culture fit (Friedman, 2006; Friedman et al., 2010).

An implicit assumption in these accounts is that nations/cultures are either categorically collectivistic or individualistic. Prevailing assumptions expect both attachment anxiety and avoidance to correlate positively with collectivism and negatively with individualism, and individualism and collectivism to moderate the relation between attachment and psychological outcomes at the culture level. It remains to be seen whether these assumptions apply at the individual level of analysis as constructs may relate differently at the culture or individual level (Hofstede, 1980; Schwartz, 2009). Further, the predictions concerning avoidance needs re-examining. Avoidance appears to share more conceptual similarities with individualism than collectivism, with both avoidance and individualism stressing self-sufficiency and independence, whereas the defining characteristics of avoidance (maintaining emotional distance, discomfort with closeness) are conceptually dissimilar to those of collectivism (interdependence and connectedness). Theoretically, it makes more sense that avoidance would be positively correlated with individualism and negatively correlated with collectivism. This prediction also fits better with explana- tions that avoidance more strongly predicts negative outcomes in East Asian than Western cultures due to poorer fit of its characteristics (e.g., emotional restraint, maintaining interpersonal distance) in a collectivistic compared to individualistic context.

While the explanations evoking individualism and collectivism to account for cultural differences in attachment styles are appealing, most studies have made assumptions about national/cultural differences without directly assessing and examining their association with attachment. Such assumptions may be unsound, as Oyserman et al. (2002) found in a meta-analysis that showed national comparisons of individualism and collectivism vary depending on how the construct is measured and that results were not always in accord with common impressions. Irrespective, there are few studies that have properly measured individualism and collectivism and also directly examined their association with adult attachment.

\section{Studies on Relationships Between Adult Attachment, Individualism, and Collectivism}

We located three studies that report on the associations between attachment, individualism, and collectivism as individual differences (Frías, Shaver, \& DíazLoving, 2014; Wang \& Mallinckrodt, 2006; Wang \& Ratanasiripong, 2010). These studies found attachment anxiety showed a positive association with collectivism (Frías et al., 2014; Wang \& Mallinckrodt, 2006), but no significant association with individualism (Frías et al., 2014; Wang \& Mallinckrodt, 2006; Wang \& Ratanasiripong, 2010), partially supporting the assumptions in the literature. Results for attachment avoidance were less consistent and differed across cultural groups and studies. Avoidance showed negative or non-significant associations with collectivism (Frías et al., 2014; Wang \& Mallinckrodt, 2006), and negative, positive, or non-significant associations with independence (Frías et al., 2014; Wang \& Mallinckrodt, 2006; Wang \& Ratanasiripong, 2010). These differences in results may have been due to differences in cultural groups sampled.

Importantly, Wang and Ratanasiripong (2010) was the only study to have examined the moderating effect of individualism on the relationship between attachment orientations and psychological functioning (i.e., emotional expressivity, social difficulties, and depressive symptoms) involving an East Asian sample (i.e., Chinese Americans). Controlling for avoidance, they found that individualism moderated the relation between attachment anxiety and social difficulties. At low and median individualism levels, attachment anxiety was associated with more social difficulties, but this trend was reversed at high individualism levels. The authors speculated that Chinese Americans with higher individualism might have acculturated better and enjoy better person-culture fit 
to mainstream American culture, which might provide them with alternative sources of self-esteem to mitigate the harmful aspects of their attachment anxiety.

While these studies have furthered our understanding of the relations between attachment orientations and culture-related variables, they have limitations and were not necessarily intentionally conducted to understand the systematic associations between individualismcollectivism and adult attachment differences across Western and East Asian populations. For instance, Wang and Ratanasiripong (2010) only measured individualism and not collectivism and sampled Asian Americans without a comparison sample. Frías et al. (2014) sampled U.S. and Mexican participants and did not focus on East-West comparisons. Wang and Mallinckrodt's (2006) purpose had been to assess the conceptual equivalence of 'ideal attachment' and they did not examine the associations between actual attachment orientations and individualism-collectivism in their samples.

\section{The Present Study}

Overall, attempts to link differences in adult attachment orientations to cultural influences are largely based on inferences about culture-level differences in individualism and collectivism, with few studies that acknowledge within-culture individual differences. Using samples of Singaporean (Asian) and Australian (Western) young adults, this study examines the associations between individual differences in adult attachment orientations and personal characteristics in individualism and collectivism, and their moderating role in the relation between attachment and psychological outcomes. In view of existing findings and theoretical considerations, we propose the following hypotheses.

Hypothesis Ia - Culture level comparisons Common assumptions in the literature hold that those from cultures/ethnicities of East Asian/Chinese origins should rate themselves higher in collectivism and lower in individualism than those from cultures/ethnicities of Western/Caucasian origins (Friedman, 2006; Hofstede, 1980). At the same time, adult attachment studies that compared culture-level means often found East Asians to report higher attachment anxiety and avoidance than Westerners (e.g., Friedman et al., 2010; Lu et al., 2009). Thus, we expect Singaporeans to report higher attachment anxiety and avoidance than Australians.

Hypothesis Ib - Individualism, collectivism, and attachment If differences in attachment anxiety are associated with individual differences in individualism and collectivism (e.g., Wang \& Mallinckrodt, 2006), irrespective of country of origin, we would expect individuals with high levels of collectivism or low levels of individualism to report more attachment anxiety than those with high levels of individualism or low levels of collectivism.
On the other hand, based on the definitions of avoidance, individualism and collectivism, we would expect individuals with high levels of individualism or low levels of collectivism to report more attachment avoidance than individuals with low levels of individualism and high levels of collectivism.

Hypothesis 2 - Attachment and psychological health Consistent with existing literature (e.g., Friedman, 2006; Mak et al., 2010), attachment anxiety will predict poorer psychological outcomes in both Australians and Singaporeans. Attachment avoidance, on the other hand, will be a weaker predictor of psychological health outcomes (Mikulincer \& Shaver, 2007).

Hypothesis 3 - Individualism and collectivism as moderators We expect that individualism and collectivism will moderate the relationship between attachment anxiety/avoidance and psychological outcomes. Relatively collectivistic people view their self as more interconnected with others and stress relational harmony and duty to the in-group. A personal view of self as highly collectivistic is likely to exacerbate fears of rejection, abandonment, and hypervigilance to these signs associated with attachment anxiety. A strong view of self as interdependent with others (high collectivism) is also in conflict with preferences for maintaining independence and emotional distance with others associated with avoidance, which may evoke and intensify avoidance fears for closeness and emotional dependency on others. Thus, attachment anxiety and avoidance are expected to predict worse psychological outcomes more strongly among individuals who rate themselves to be high rather than low on collectivism. On the other hand, relatively individualistic people define their self more with personal characteristics, stressing independence, which might act as a buffer to one's fears associated with attachment anxiety. This emphasis on independence and self-sufficiency among individualistic individuals is also congruent with similar preferences of attachment avoidance. Thus, attachment anxiety and avoidance are expected to predict negative symptoms less strongly among individuals who rate themselves to be high rather than low on individualism.

\section{Method}

\section{Participants and Procedure}

Student volunteers aged between 18 and 29 years were recruited from universities in a predominantly Western cultural setting (the Australian National University, Australia) and a predominantly Chinese cultural setting (Nanyang Technological University, Singapore) and completed an online survey in English as part of a larger study examining interpersonal relationships and psychological functioning. In Singapore, English is the official language and main medium of instruction in educational institutions. Participants had spent at least 
10 years living in Australia or Singapore. The final sample of Australians consisted of 43 males (30.1\%) and 100 females $(69.9 \%)$. Their mean age was 19.97 years $(S D=2.20$ years). Of this sample, $105(73.4 \%)$ reported they were of European/Caucasian background, 13 (9.1\%) Asian excluding Chinese (e.g., Indian, Japanese, Filipino), 11 (7.7\%) Chinese, and 14 (9.8\%) Other Ethnicity. At the time of study, 59 (41.3\%) were in a romantic relationship, $84(58.7 \%)$ were not, and 36 $(25.2 \%)$ had never been in a relationship.

The final sample of Singaporeans consisted of 47 males $(32.2 \%)$ and 99 females (67.8\%). Their mean age was 21.56 years $(S D=1.76)$. Participants' ethnicities were: 137 (93.8\%) Chinese, 8 (5.5\%) Other Asian (e.g., Indian, Punjabi, Malay), and 1 (.7\%) Mixed Ethnicity (e.g., Eurasian). At the time of study, $47(32.2 \%)$ were in a romantic relationship, $99(67.8 \%)$ were not, and 70 $(47.9 \%)$ had never been in a relationship. The Australian sample was on average 1.6 years younger than the Singaporean sample, $t(1,287)=6.75, p<.001$, reflecting structural differences in educational systems. The Australian and Singaporean samples did not differ significantly in their gender ratio, $\chi^{2}(1)=.15, n s$, or the proportion of participants with a romantic partner at the time of study, $\chi^{2}(1)=2.56$, ns.

\section{Measures}

Attachment General attachment orientations were assessed with a modified version of the Experiences in Close Relationships-Relationships Structures scale (ECRRS; Fraley, Heffernan, Vicary, \& Brumbaugh, 2011; Wilkinson, 2011), which comprises 14 items to measure attachment Anxiety (7 items) and Avoidance (7 items). Participants were asked to think about 'all the people you know in general' and rate their agreement with each item using a 7-point scale $(1=$ strongly disagree; $7=$ strongly agree). Examples of items are: 'I'm afraid that people may abandon me' (Anxiety); 'I don't feel comfortable opening up to people' (Avoidance). Higher scores indicate higher attachment anxiety or avoidance. In Fraley et al. (2011), Cronbach's alphas ranged from .83 to .87 for Anxiety, and .81 to .95 for Avoidance. In the current study, Cronbach's alphas for Anxiety were .90 (Australians) and .87 (Singaporeans), and for Avoidance were 89 (Australians) and .76 (Singaporeans).

Individualism and collectivism Cultural orientations were assessed with the Individualism-Collectivism scale (Triandis \& Gelfand, 1998), which has four subscales that assess horizontal and vertical forms of individualism and collectivism: Vertical Individualism (VI; eight items), Horizontal Individualism (HI; five items), Vertical Collectivism (VC; six items), and Horizontal Collectivism (HC; eight items). Mean scores of the HI items were used to derive participants' personal endorsement of individualism while mean scores of HC and $\mathrm{VC}$ items were collapsed to derive their personal endorsement of collectivism. ${ }^{2}$ The 14 Collectivism items assess a view of the self as interdependent with others and having a sense of duty towards the in-group (e.g., 'My happiness depends very much on the happiness of those around me', 'Family members should stick together, no matter what sacrifices are made'). The six Individualism items assess a view of the self as autonomous and stress personal independence (e.g., 'I'd depend on myself than others', 'Being a unique individual is important to me'). Participants were asked to rate their agreement with each item on a 9-point scale $(1=$ strongly disagree; $5=$ unsureldoes not apply; $9=$ strongly agree). Higher scores indicate a stronger orientation. These measures have demonstrated divergent and convergent validity and have acceptable subscale reliabilities ranging from .67 to .74 (Singelis et al., 1995). In the current study, the Cronbach's alphas for Individualism were 75 (Australians) and .76 (Singaporeans), and for Collectivism were .83 (Australians) and .74 (Singaporeans).

Psychological outcomes The DASS-21 (Lovibond \& Lovibond, 1995) was administered to assess psychological outcomes. It has three subscales (seven items each) that measure the symptoms of depression (e.g., 'I felt downhearted and blue'), stress (e.g., 'I found it difficult to relax'), and anxiety (e.g., 'I felt I was close to panic'). Participants rated how each item applied to them over the past week using a 4-point scale $(0=$ not at all; $3=$ very much or most of the time). All items were summed to yield an overall psychological outcomes (Negative Emotional State) score. Higher scores indicate more negative symptoms or poorer outcomes. The internal reliabilities for the Depression, Anxiety and Stress subscales and total scale ranged from .82 to .93 in non-clinical Western samples (Henry \& Crawford, 2005), and .74 to .88 in Asian samples (Norton, 2007). The internal reliabilities for the overall scale in this study were high. Cronbach's alphas were .93 (Australians) and .92 (Singaporeans).

\section{Results}

As expected, comparisons of means (Table 1) showed that Singaporeans reported significantly higher levels of collectivism than Australians (H1a), $t(287)=4.71, p<.001$, as well as significantly higher levels of attachment anxiety than Australians (H1a), $t(287)=2.51, p<.05$. A one-way ANCOVA showed that the samples differed significantly in Anxiety even after age, the number of years participants had lived in their respective country, and relationship status were controlled for, $F(1,283)=7.24$, $p<.01, \eta_{p}^{2}=.025$. Contrary to expectations, however, Singaporeans and Australians were not significantly different in their mean level of Individualism or Avoidance, $\mathrm{H} 1 \mathrm{a}, t(287)=.38$ and $.91, n s$, respectively.

Of more interest to our study were the associations between attachment, individualism, and collectivism. 


\section{TABLE I}

Means and Standard Deviations for Australians and Singaporeans

\begin{tabular}{|c|c|c|c|c|}
\hline \multirow[b]{2}{*}{ Variables } & \multicolumn{2}{|c|}{$\begin{array}{c}\text { Australians } \\
(n=143)\end{array}$} & \multicolumn{2}{|c|}{$\begin{array}{l}\text { Singaporeans } \\
\quad(n=146)\end{array}$} \\
\hline & $M$ & $S D$ & $M$ & $S D$ \\
\hline \multicolumn{5}{|l|}{ Attachment orientation } \\
\hline Anxiety & 3.45 & 1.46 & $3.84^{*}$ & 1.17 \\
\hline Avoidance & 3.67 & 1.29 & 3.79 & .94 \\
\hline \multicolumn{5}{|l|}{ Cultural orientation } \\
\hline Collectivism & 6.26 & 1.16 & $6.83^{* *}$ & .90 \\
\hline Individualism & 6.88 & 1.28 & 6.94 & 1.18 \\
\hline Negative emotional state & 16.34 & 11.91 & 17.66 & 10.95 \\
\hline
\end{tabular}

Note: ${ }^{*} p<.05,{ }^{* *} p<.001$.

Pearson product correlations provided partial support for $\mathrm{H} 1 \mathrm{~b}$. As hypothesised, Avoidance was significantly correlated with Individualism, $r=.34, p<.001$, and Collectivism, $r=-.31, p<.001$, in the appropriate directions. Contrary to our hypothesis, attachment anxiety was not significantly correlated with either Collectivism or Individualism. In support of $\mathrm{H} 2$, both Anxiety, $r=.42$ $p<.001$, and Avoidance, $r=.23 p<.001$, were correlated with Negative Emotional State, with Avoidance showing a weaker correlation, Steigers $Z=3.00, p<.01$.

Table 2 shows the intercorrelations for the major variables separately for the two samples. Multiple regression analyses were employed to evaluate the hypotheses involving moderation hypotheses. All predictor variables were mean-centred or dummy-coded as appropriate, with appropriate product terms employed as interaction terms for the moderation analyses (Aiken \& West, 1991). To test for H2, Negative Emotional State was regressed on Anxiety and Avoidance. As hypothesised, both Anxiety and Avoidance significantly predicted worse negative symptoms, $F(2,286)=33.66$, $p<001$. Further, in support of $\mathrm{H} 2$, attachment anxiety (standardised $\beta=.39$,

\section{TABLE 2}

Intercorrelations Between Attachment Orientations, Cultural Orientations, and Negative Emotional State for Australians $(n=143)$ and Singaporeans $(n=146)$

\begin{tabular}{lccclcc}
\hline Variable & 1 & 2 & 3 & 4 & 5 \\
\hline Attachment anxiety & & $.36^{* *}$ & .14 & -.07 & $.41^{* *}$ \\
$\begin{array}{l}\text { Attachment } \\
\quad \text { avoidance }\end{array}$ & .16 & & $.42^{* *}$ & $-.37^{* *}$ & $.28^{* *}$ \\
Individualism & -.12 & $.23^{* *}$ & & $-.17^{*}$ & $.20^{*}$ \\
Collectivism & -.04 & $-.27^{* *}$ & .04 & & -.05 \\
$\quad \begin{array}{l}\text { Negative emotional } \\
\quad \text { state }\end{array}$ & $.43^{* *}$ & .16 & .08 & -.15 & \\
\hline
\end{tabular}

Note: Australians (above the diagonal), Singaporeans (below the diagonal). ${ }^{*} p<.05 .{ }^{* *} p<.001$.

$p<.001)$ was a stronger predictor of negative symptoms than avoidance (standardised $\beta=.12, p<.05$ ).

To test for the hypothesised moderation of cultural orientation on the relation between attachment anxiety/avoidance and negative symptoms in H3, four parallel hierarchical regressions regressing Negative Emotional State on Anxiety (or Avoidance), Culture, and Collectivism (or Individualism), and their interaction terms were conducted. For instance, for analyses involving Anxiety as the predictor of interest, Avoidance was entered as a covariate in step 1. In step 2, Anxiety, Culture, and Collectivism (or Individualism) were entered. In step 3, Anxiety $\times$ Collectivism (or Individualism) was entered. Other possible two-way and three-way interaction terms were entered in steps 3 and 4, respectively, to control for higher-order effects (Aiken \& West, 1991).

When Collectivism was tested as the moderator in the relation between Attachment Anxiety and Negative Emotional State, the interaction term explained a significant increase in the variance explained for Negative Emotional State, $\Delta R^{2}=.03, \Delta F(3,281)=3.48$, $p<.05$ (see Table 3a). Thus, Collectivism significantly

\section{TABLE 3a}

Hierarchical Regression Analyses on the Moderating Effects of Collectivism on the Relation Between Attachment Anxiety and Negative Emotional State $(N=289)$

\begin{tabular}{|c|c|c|c|c|c|c|c|c|}
\hline Step & B & $\beta$ & $t$ & $R^{2}$ & Adjusted $R^{2}$ & $\Delta R^{2}$ & $\Delta F$ & $d f$ \\
\hline Step model & & & & .052 & .048 & .052 & $15.66^{* * *}$ & $(I, 287)$ \\
\hline AV & 2.31 & .23 & $3.96^{* * *}$ & & & & & \\
\hline Step model & & & & .191 & .180 & .140 & $16.36^{* * *}$ & $(3,284)$ \\
\hline $\mathrm{AN}$ & 3.35 & .39 & $6.95^{* * *}$ & & & & & \\
\hline Collectivism & -.36 & -.03 & -.57 & & & & & \\
\hline Culture & .09 & .00 & .07 & & & & & \\
\hline Step model & & & & .220 & .201 & .029 & $3.48^{*}$ & $(3,28 I)$ \\
\hline AN $\times$ Collectivism & 1.13 & .16 & $2.83 * *$ & & & & & \\
\hline Culture $\times$ AN & .12 & .01 & .13 & & & & & \\
\hline Culture $\times$ Collectivism & -1.24 & -.07 & -1.02 & & & & & \\
\hline Step model & & & & .222 & .200 & .002 & .58 & $(I, 280)$ \\
\hline AN $\times$ Collectivism $\times$ Culture & -.66 & -.05 & -.76 & & & & & \\
\hline
\end{tabular}

Note: ${ }^{*} p<.05 .{ }^{* *} p<.01 .{ }^{* * *} p<.001$ 


\section{TABLE 3b}

Hierarchical Regression Analyses on the Moderating Effects of Individualism on the Relation Between Attachment Anxiety and Negative Emotional State $(N=289)$

\begin{tabular}{|c|c|c|c|c|c|c|c|c|}
\hline Step & $B$ & $\beta$ & $t$ & $R^{2}$ & Adjusted $R^{2}$ & $\Delta R^{2}$ & $\Delta F$ & $d f$ \\
\hline Step model & & & & .052 & .048 & .052 & $15.66^{* * *}$ & $(\mathrm{I}, 287)$ \\
\hline AV & 2.31 & .23 & $3.96^{* * *}$ & & & & & \\
\hline Step model & & & & .201 & .189 & .149 & $17.62^{* * *}$ & $(3,284)$ \\
\hline AN & 3.41 & .40 & $7.09^{* * *}$ & & & & & \\
\hline Individualism & .99 & .11 & 1.89 & & & & & \\
\hline Culture & -.16 & -.01 & -.13 & & & & & \\
\hline Step model & & & & .217 & .197 & .016 & 1.96 & $(3,28 I)$ \\
\hline AN $\times$ Individualism & -.75 & -.12 & -2.14 & & & & & \\
\hline Culture $\times$ AN & .99 & .07 & 1.05 & & & & & \\
\hline Culture $\times$ Individualism & .35 & .03 & .34 & & & & & \\
\hline Step model & & & & .232 & .210 & .015 & $5.58^{*}$ & $(I, 280)$ \\
\hline AN $\times$ Individualism $\times$ Culture & -1.73 & -.15 & $-2.36^{*}$ & & & & & \\
\hline
\end{tabular}

Note: ${ }^{*} p<.05 .{ }^{* *} p<.01 .{ }^{* * *} p<.001$.

moderated the relationship between Attachment Anxiety and Negative Emotional State, supporting H3. As can be seen in Figure 1, Attachment Anxiety predicted Negative Emotional State more strongly at 1 standard deviation above the mean of Collectivism (unstandardised simple slope $=4.66, t=5.51, p<.001)$ than at 1 standard deviation below the mean of Collectivism (unstandardized simple slope $=2.24, t=3.35, p<.001$ ). No other interaction effects were significant.

When Individualism was examined as a moderator in the relation between Anxiety and Negative Emotional State, although adding Anxiety $\times$ Individualism in step 3 did not add significantly to the explanation of the variance of negative symptoms, $\Delta R^{2}=.02, \Delta F(3,281)=1.96$, $n s$, adding the three-way interaction term Anxiety $\times$ Individualism $\times$ Culture in step 4 did, $\Delta R^{2}=.02, \Delta F(1$, $280)=5.58, p<.05$ (see Table $3 \mathrm{~b}$ ). Individualism signif- icantly moderated the relationship between Anxiety and psychological symptoms among Singaporeans but not Australians, providing qualified support for H3. For Singaporeans, Anxiety predicted more symptoms at 1 standard deviation below the mean of Individualism (unstandardised simple slope $=6.36, t=6.12, p<.001$ ) but not at 1 standard deviation above the mean of Individualism (unstandardised simple slope $=1.75, t=1.69$, ns; slope difference: $t=-3.18, p<.01$; see Figure 2). For Australians, Attachment Anxiety predicted a higher Negative Emotional State similarly at 1 standard deviation below (unstandardised simple slope $=3.16, t=3.72, p<.001$ ) and 1 standard deviation above the mean of Individualism (unstandardised simple slope $=2.80, t=3.64, p<.001$; slope difference: $t=.36, n s$ ), contrary to predictions.

When Collectivism was tested as a moderator in the relation between Avoidance and Negative Emotional

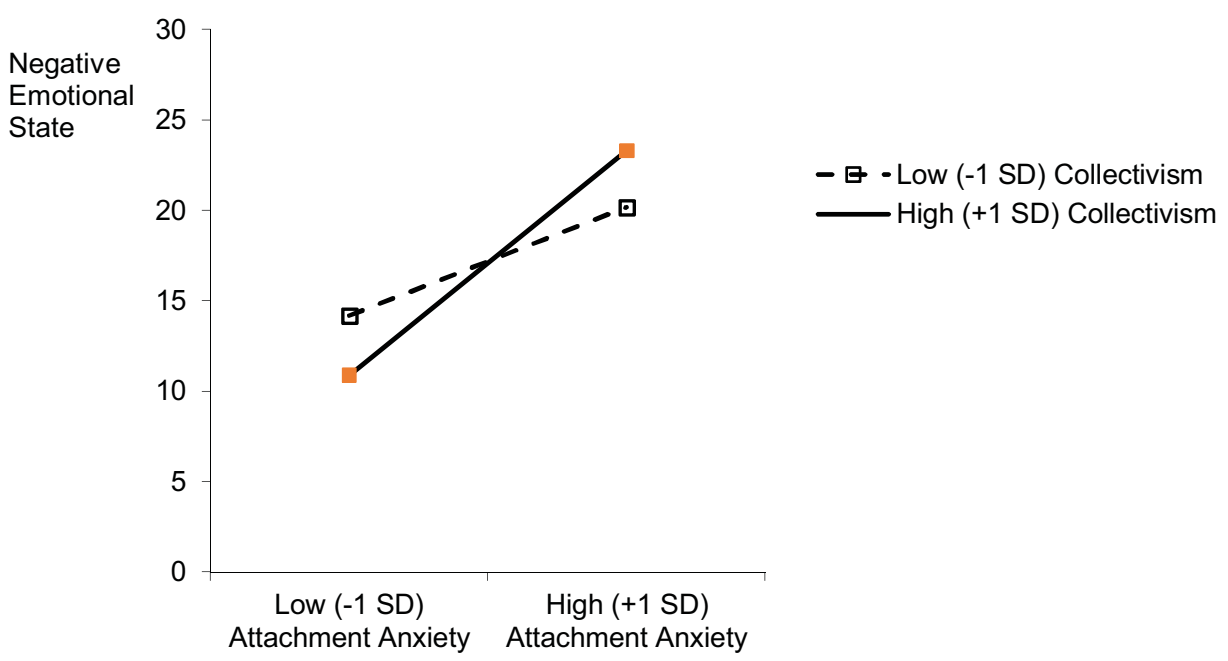

FIGURE I

Simple slopes of attachment anxiety predicting negative emotional state at I SD below and I SD above the mean of collectivism. 


\section{TABLE 4a}

Hierarchical Regression Analyses on the Moderating Effects of Collectivism on the Relation Between Attachment Avoidance and Negative Emotional State $(N=289)$

\begin{tabular}{|c|c|c|c|c|c|c|c|c|}
\hline Step & B & $\beta$ & $t$ & $R^{2}$ & Adjusted $R^{2}$ & $\Delta R^{2}$ & $\Delta F$ & $d f$ \\
\hline Step model & & & & .178 & .175 & .178 & $62.26^{* * *}$ & $(I, 287)$ \\
\hline AN & 3.62 & .42 & $7.89^{* * *}$ & & & & & \\
\hline Step model & & & & .191 & .180 & .013 & 1.59 & $(3,284)$ \\
\hline AV & 1.06 & .II & $\mathrm{I} .77$ & & & & & \\
\hline Collectivism & -.36 & -.03 & -.57 & & & & & \\
\hline Culture & .09 & .00 & .07 & & & & & \\
\hline Step model & & & & .197 & .177 & .005 & .59 & $(3,28 I)$ \\
\hline AV $\times$ Collectivism & -.05 & $-.0 \mathrm{I}$ & -.11 & & & & & \\
\hline Culture $\times \mathrm{AV}$ & -.47 & -.03 & -.37 & & & & & \\
\hline Culture $\times$ Collectivism & -1.73 & -.10 & -1.34 & & & & & \\
\hline Step model & & & & .217 & .195 & .021 & $7.44^{* *}$ & $(I, 280)$ \\
\hline AV $\times$ Collectivism $\times$ Culture & -3.14 & -.18 & $-2.73^{* *}$ & & & & & \\
\hline
\end{tabular}

Note: ${ }^{*} p=.05 .{ }^{* *} p<.01 .{ }^{* * *} p<.001$.

State, although adding Avoidance $\times$ Collectivism in step 3 did not add significantly to the explanation of Negative Emotional State, $\Delta R^{2}=.01, \Delta F(3,281)=.59, n s$, adding the three-way term Avoidance $\times$ Collectivism $\times$ Culture in step 4 did, $\Delta R^{2}=.02, \Delta F(1,280)=7.44$, $p<.01$ (see Table 4a). For Australians, Avoidance showed trends of predicting worse negative symptoms at 1 standard deviation above the mean of Collectivism (unstandardised simple slope $=2.19, t=1.93, p=.055$ ) but not at 1 standard deviation below the mean of Collectivism (unstandardised simple slope $=0.98, t=1.25$, $n s$; slope difference: $t=1.07$, ns; see Figure 3). For Singaporeans, on the other hand, Attachment Avoidance predicted higher scores on Negative Emotional State at $1 S D$ below the mean of Collectivism (unstandardized simple slope $=4.46, t=2.55, p<.05)$ and opposite trends of predicting less negative symptoms at 1 standard deviation above the mean of Collectivism although this association did not reach significance levels (unstandardised simple slope $=1.08, t=0.89$, ns; slope difference: $t=2.49, p<.05)$. Thus, H3 was not supported.

When Individualism was tested as a moderator in the relation between Avoidance and Negative Emotional State, adding Avoidance $\times$ Individualism in step 3 did not significantly increase in the explanation of Negative Emotional State, $\Delta R^{2}=.00, \Delta F(3,281)=.39$, ns (see Table 4b). There were no other significant higher order effects. Thus, in this respect $\mathrm{H} 3$ was not supported. Overall, H3 received qualified support when Individualism and Collectivism were examined as moderators in the relation between attachment anxiety and psychological symptoms but was not supported when Individualism

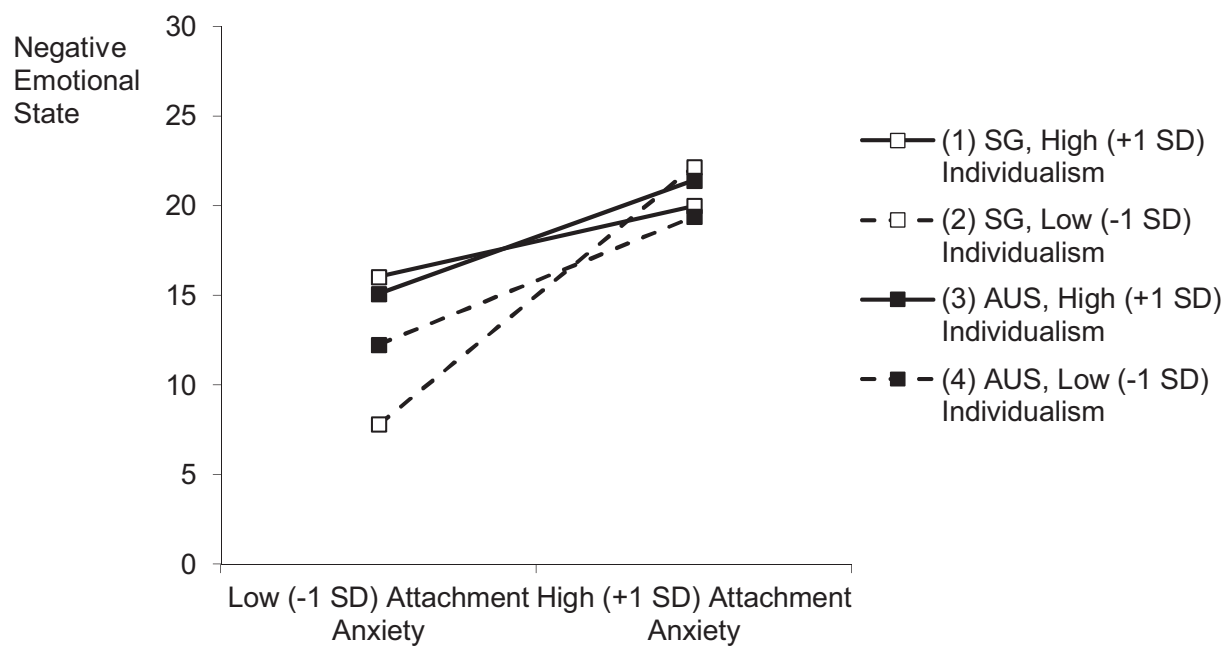

\section{FIGURE 2}

Simple slopes of attachment anxiety predicting negative emotional state at I SD below and I SD above the mean of individualism for Australians (AUS, $n=$ 143) and Singaporeans (SG, $n=146)$. 


\section{TABLE 4b}

Hierarchical Regression Analyses on the Moderating Effects of Individualism on the Relation Between Attachment Avoidance and Negative Emotional State $(N=289)$

\begin{tabular}{|c|c|c|c|c|c|c|c|c|}
\hline Step & B & $\beta$ & $t$ & $R^{2}$ & Adjusted $R^{2}$ & $\Delta R^{2}$ & $\Delta F$ & $d f$ \\
\hline Step model & & & & .178 & .175 & .178 & $62.26 * * *$ & $(\mathrm{I}, 287)$ \\
\hline AN & 3.62 & .42 & $7.89^{* * *}$ & & & & & \\
\hline Step model & & & & .201 & .189 & .022 & $2.64^{*}$ & $(3,284)$ \\
\hline AV & .78 & .08 & 1.31 & & & & & \\
\hline Individualism & .99 & .11 & 1.89 & & & & & \\
\hline Culture & -.16 & -.01 & -.13 & & & & & \\
\hline Step model & & & & .204 & .184 & .003 & .39 & $(3,28 I)$ \\
\hline AV $\times$ Individualism & .45 & .06 & 1.07 & & & & & \\
\hline Culture $\times$ AV & .13 & .01 & .11 & & & & & \\
\hline Culture $\times$ Individualism & -.22 & -.02 & -.21 & & & & & \\
\hline Step model & & & & .207 & .184 & .003 & .97 & $(I, 280)$ \\
\hline AV $\times$ Individualism $\times$ Culture & .89 & .07 & .98 & & & & & \\
\hline
\end{tabular}

Note: ${ }^{*} p=.05 .{ }^{* *} p<.01 .{ }^{* * *} p<.001$.

and Collectivism were evaluated as moderators in the relation between Attachment Avoidance and the measure of distress.

\section{Discussion}

The results of this study provided mixed support for our hypotheses. In line with the prevailing literature, Singaporeans reported higher attachment anxiety and collectivism than Australians (H1a). Contrary to expectations, however, Singaporeans did not show significant differences in attachment avoidance and individualism compared to Australians. These findings partially replicate typical findings in the literature that Asians report significantly higher levels of attachment insecurity than Westerners (e.g., Cheng \& Kwan, 2008; Ho et al., 2010; Lu et al., 2009). That Singaporeans and Australians reported similar levels of avoidance and individualism may suggest that either or both populations may represent less typical Western or East Asian culture. For instance, Singapore may be higher in individualism because it is a cosmopolitan culture that has received strong Western influences due to its highly globalised economy. Alternatively, while it is conventionally assumed that East Asians are more collectivistic and less individualistic than Westerners, a recent meta-analysis has shown that culture-level mean differences in individualism-collectivism do not always conform to those expectations (Oyserman et al., 2002). Moreover, it has been argued that culture-level mean comparisons of subjective ratings may be unreliable, as different cultural groups are likely to use different social referents to anchor their personal responses (Heine, Lehman,

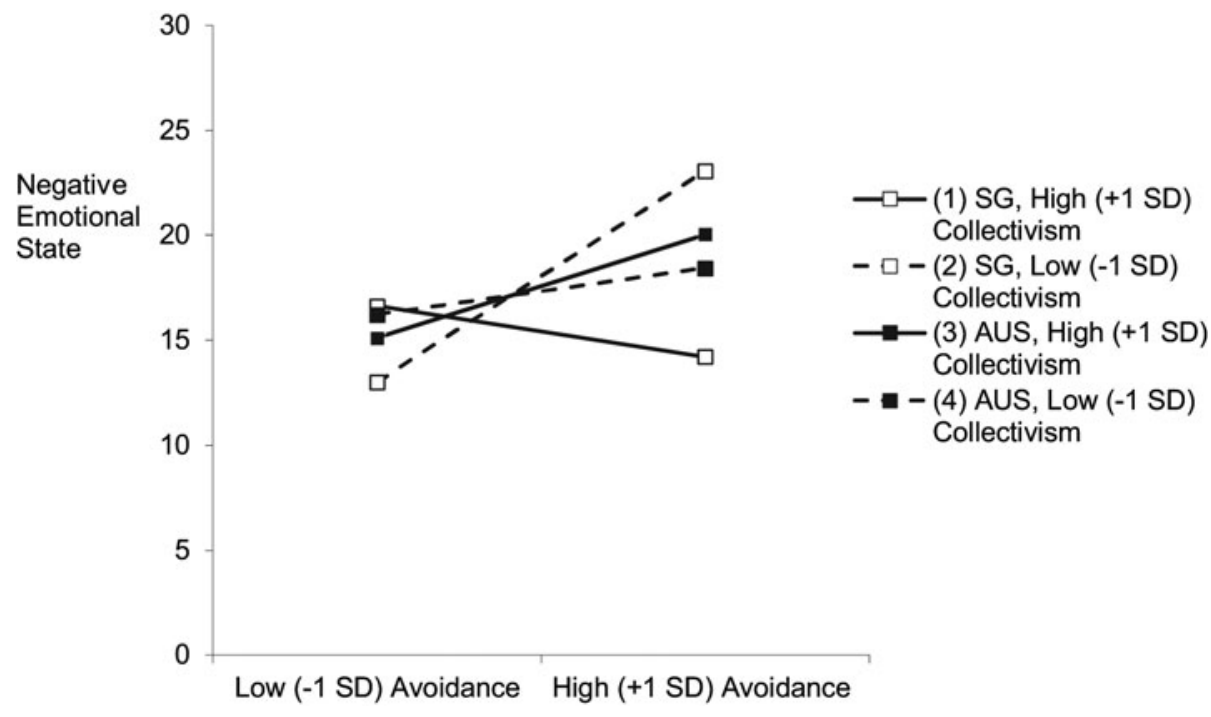

FIGURE 3

Simple slopes of attachment avoidance predicting negative emotional state at I SD below and I SD above the mean of collectivism for Australians (AUS, $n=$ 143) and Singaporeans (SG, $n=146$ ). 
Peng, \& Greenholtz, 2002). Thus, it has been argued that a better approach to understand how cultural influences relate to constructs of interest is to directly assess their associations at the individual level (Heine et al., 2002). In any case, our findings underscore the importance of explicitly assessing both individualism and collectivism, as assumptions about their 'culture' levels may not hold true.

In relation to attachment orientations, our hypotheses were partially supported in that individualism and collectivism correlated with attachment avoidance such that participants with low collectivism or high individualism tended to have higher levels of avoidance than those with high collectivism or low individualism. Our study replicated previous results showing non-significant associations between attachment anxiety and individualism (Frías et al., 2014; Wang \& Mallinckrodt, 2006; Wang \& Ratanasiripong, 2010), and the directions of associations between avoidance and individualism as well as collectivism in Frías et al. (2014). However, contrary to expectations, attachment anxiety did not correlate significantly with individualism and collectivism. Thus, we did not find, as others have (e.g., Frías et al., 2014), that attachment anxiety is positively associated with collectivism.

With respect to attachment avoidance, we argued that it makes more conceptual sense that avoidance is positively associated with individualism (and negatively associated with collectivism) because both avoidance and individualism share definitional similarities in their emphases on the self to maintain independence and selfsufficiency (Brennan et al., 1998; Singelis et al., 1995). This is supported by our results (also Frías et al., 2014). However, our results do not support the implied direction of associations between attachment avoidance and cultural orientations in the literature, as well as the expectations that differences in attachment anxiety may be associated with differences in individualism-collectivism, at least at the individual level of analysis. Having said that, a lack of evidence that individual differences in individualism and collectivism are associated with attachment anxiety in our study does not preclude the possibility of relationships between individualism, collectivism, and attachment orientations at the culture level. This is because the pattern of associations observed between constructs at the individual level cannot be assumed to apply at the culture level and vice versa (Hofstede, 1980; Oyserman et al., 2002; Schwartz, 2009). Schmitt et al.'s (2004) cross-cultural study spanning 62 cultural regions and 58 nations found that at the culture level of analysis, national levels of preoccupied attachment correlated negatively with national levels of individualism. Their study offers some promise that culture level differences in individualism and collectivism may indeed relate to culture level differences in attachment orientations.

In support of $\mathrm{H} 2$, attachment anxiety was a stronger predictor of higher levels of psychological symptoms across cultures. Interestingly, avoidance was not significantly correlated with negative symptoms for Singaporeans when correlations between attachment orientations and negative symptoms were examined within each culture. These results support common findings that attachment anxiety is more consistently associated with poorer outcomes such as depressive symptoms or negative mood than avoidance (Mikulincer \& Shaver, 2007). Our results add to the literature in demonstrating that the relation between dysfunctional attachment representations (attachment anxiety) and poorer psychological outcomes is robust across East Asian and Western cultures (e.g., Friedman, 2006; Mak et al., 2010; Wei et al., 2004). At the same time, differential associations between avoidance and negative symptoms across cultures suggest that avoidance does not exert similar adverse impacts on psychological outcomes among Singaporeans and Australians.

Our hypothesis (H3) that individualism and collectivism would moderate the relationship between attachment anxiety and psychological wellbeing received qualified support. As hypothesised, regardless of cultural origin, attachment anxiety predicted poorer psychological outcomes more strongly among individuals with higher than lower personal endorsement of collectivism. Our results suggest that high attachment anxiety may be even more detrimental to one's psychological health when one is also highly collectivistic, that is, views the self as strongly interdependent with others. When one already has high attachment anxiety, viewing the self as interdependent with others may exacerbate the fear of abandonment and rejection, increasing negative emotions. On the other hand, low levels of collectivism may serve as a 'buffer' that makes one less hypervigilant to social cues that could be interpreted as rejection, protecting one from distress arising from attachment anxiety.

Examination of the collectivism items reveal that they assess concerns about maintaining group harmony ('It is important to me to maintain harmony in my group'), the extent that close others form an inherent part of the self ('My happiness depends very much on the happiness of those around me'), as well as acceptance of duties, especially towards the family ('It is my duty to take care of my family, even when I have to sacrifice what I want'). Scholars have argued that collectivism and individualism may be better defined as a multifaceted rather than a unitary construct that comprises different content domains (Singelis et al., 1995). Supporting this view, a content-analysis of existing individualism and collectivism scales identified up to eight content domains of individualism and collectivism that are not assessed to the same extent, or sometimes not assessed at all, across scales (Oyserman et al., 2002). It is unclear whether the collectivism scale we employed assessed all of these content domains adequately or to the same extent. Thus, further systematic study is needed to determine whether different aspects of collectivism moderate the 
association between attachment anxiety and psychological outcomes.

The third hypothesis, that attachment anxiety would predict worse negative emotions at lower rather than higher individualism, also received qualified support. We found that attachment anxiety predicted negative symptoms among Singaporeans with a low but not high personal endorsement of individualism, whereas attachment anxiety predicted Australians' negative symptoms similarly regardless of their individualism levels. We had argued that high individualism would partially mitigate the fears of abandonment and rejection associated with attachment anxiety because of its emphasis on independence and self-reliance (see also Wang \& Ratanasiripong, 2006). Examining the individualism scale items revealed that they assess independence, self-sufficiency, and one's personal identity (e.g., 'I rather depend on myself than others', 'My personal identity, independent of others, is very important to me'). Our results suggest that valuing these qualities appears to buffer the negative effects of attachment anxiety very effectively for Singaporeans, but not for Australians. Such differential moderating effects of individualism across the cultures suggest that there may be other cultural/contextual factors influencing psychological outcomes that are not investigated in this study.

Our hypothesis that individualism and collectivism would moderate the relation between attachment avoidance and psychological outcomes was not supported. On the other hand, when collectivism was examined as a moderator, it only emerged as a significant effect among Singaporeans (not Australians) and in unexpected ways. More specifically, attachment avoidance predicted worse negative symptoms among Singaporeans who were low (but not high) on collectivism, contrary to predictions that high collectivism may evoke stronger avoidance fears leading to poorer psychological outcomes. Instead, it appears that Singaporeans low on collectivism were more susceptible to poorer psychological outcomes associated with avoidance than those high on collectivism. For Australians, also against the hypothesis, collectivism did not moderate the extent to which attachment avoidance predicted negative symptoms. These results suggest that having high collectivism, although seeming to be in conflict with avoidance tendencies, may mitigate some of the negative effects of avoidance for those living in Singapore. Such findings require replicating, and it is premature to draw strong conclusions at this point. However, they do highlight that the way personal characteristics in individualism and collectivism interact with attachment processes to influence psychological outcomes is complex and may differ across individuals coming from different cultural backgrounds, possibly due to the presence of other cultural factors that are not fully captured by self-ratings of individualism and collectivism.

Overall, our results show that personal characteristics in individualism and collectivism interact with attach- ment anxiety and avoidance in different ways to influence psychological outcomes, possibly because the two attachment orientations are associated with different concerns, fears, and responses relating to interpersonal issues. These differences appear to interact differently with individualism and collectivism in ways that are still poorly understood and need further investigation. On the whole, our results suggest that prevailing views about the associations between individualism, collectivism, and attachment orientations are more supported in the case of attachment avoidance, and prevailing views about the moderating role of individualism and collectivism in the attachmentpsychological health link are more supported in the case of attachment anxiety.

\section{Limitations and Future Directions}

We sampled two cultural groups to examine whether cultural orientations are associated with variations in attachment orientations at the individual level of analysis. Whether and how cultural orientations relate to differences in attachment orientations at the culture level of analysis remains an empirical question that our study does not address. The culture level question can only be answered by larger scale, cross-cultural studies that sample numerous nations and/or cultural groups (e.g., Schmitt et al., 2004) or meta-analyses of smaller-scale studies that have systematically assessed the relationships between cultural orientations and attachment orientations (e.g., Bakermans-Kranenburg \& van Ijzendoorn, 2009). Before the culture level question is adequately examined empirically, however, researchers should refrain from invoking cultural orientations, such as individualism and collectivism, as assumed reasons for cultural differences in attachment orientations.

Individualism and collectivism have not always been defined or operationalised consistently across studies or scales (Oyserman et al., 2002). Thus, researchers are urged to employ tighter definitions and strive for specificity in the assessment of individualism and collectivism so that meaningful conclusions can be drawn from their results (Schimmack, Oishi, \& Diener, 2005; Singelis et al., 1995). Although the individualism and collectivism scales we used appear to cover the core meaning of these constructs consensually agreed upon by researchers (Oyserman et al., 2002), the items may not have assessed all aspects to the same extent. Future studies should pay more attention to measurement issues regarding individualism and collectivism. Our study also generated some different findings across cultures that could not be accounted for by self-ratings of individualism and collectivism. If further empirical studies determine that cultural orientations cannot serve as all-encompassing explanations for cultural/individual differences in attachment patterns, other constructs should be explored. Some possibilities may be to examine the associations of attachment orientations with cultural norms or to examine the 
moderating role of person-culture fit and acculturation in the attachment-wellbeing link, aspects which were not assessed in the current study.

Importantly, the current study only focused on the attachment dimensions of anxiety and avoidance. There remains debate in the literature over whether this is the optimal approach or whether there are other aspects or alternative conceptualisations of individual differences in attachment expectancies that need to be considered (e.g., Bowles, 2010; Karantzas, Feeney, \& Wilkinson, 2010). It has been argued that attachment security, for example, is not simply the lack of insecurity (attachment anxiety and avoidance) but is constituted of positive attitudes and expectancies about close relationships, interdependency, and the self (Shaver, Mikulincer, Sahdra, \& Gross, 2016). Future research should also look at alternatives to self-report assessments of attachment such as the Adult Attachment Interview (George, Kaplan, \& Main, 1996) and the Adult Attachment Projective (George \& West, 2001).

In the current study we only examined common psychological outcomes in a non-clinical population with the DASS 21, which measures symptoms reflecting negative emotional states. While there has been extensive validation of the DASS 21 in a number of populations, including Chinese participants (Chan et al., 2012), future research should attempt to establish whether our results are replicable in clinical populations or with other indices of psychological health that reflect broader or more traitlike attributes. Like other correlational studies based on self-report measures, our study is also unable to establish causal direction for the relationships revealed and suffers from the potential measurement biases associated with self-report methodology. Future studies may employ priming techniques (e.g., Gillath, Sesko, Shaver, \& Chun, 2010; Mikulincer, Birnbaum, Woddis, \& Nachmias, 2000) to manipulate differences in attachment and/or cultural orientation levels to investigate their causal effects on response variables of interest. Finally, the generalisability of our results may be limited to the East Asian and Western undergraduates we sampled. Future studies should extend the research to other cultures and nonundergraduates.

\section{Conclusion}

By explicitly measuring individualism and collectivism, our study was able to systematically examine the associations between attachment orientations and cultural orientations, as well as the moderating effect of individualism and collectivism in the relationship between attachment orientations and psychological outcomes across cultures. By recognising within-culture individual differences in individualism and collectivism we were able to demonstrate that cultures/nations traditionally regarded as individualistic or collectivistic showed the same patterns of associations between attachment orientations, cultural orientations, and psychological outcomes. Our results also suggest that individualism and collectivism could not fully account for differences in attachment patterns and that there are probably other cultural and contextual factors moderating the relationship between attachment orientations and psychological outcomes that should be explored. While we acknowledge that research has indicated relationships between the adherence to 'Asian' values and attitudes to both psychological symptoms (e.g., Cheng \& Kwan, 2008; Iwamoto \& Liu, 2010) and seeking professional help (e.g., Hamid, Simmonds, \& Bowles, 2009; Kim \& Omizo, 2003), the current research emphasises the importance of recognising that our assumptions about cultural differences may not be correct for any individual. Stereotypes derived from perceived cultural membership may negatively impact on our clinical formulations and ability to provide appropriate assistance for individuals with relationship problems or in psychological distress.

\section{Financial Support}

This research received no specific grant from any funding agency, commercial, or not-for-profit sectors.

\section{Conflict of Interest}

None.

\section{Ethical Standards}

The authors assert that all procedures contributing to this work comply with the ethical standards of the relevant national and institutional committees on human experimentation and with the Helsinki Declaration of 1975, as revised in 2008.

\section{Endnotes}

1 Other parallel, but less common, terms that have been used in the literature for individualism-collectivism are independence-interdependence, self-construals, and Western-Eastern worldviews (Oyserman et al., 2002). For consistency, we use individualism and collectivism to replace parallel terms used in other studies when reporting their results.

2 Combining $\mathrm{HC}$ and VC scales to derive a Collectivism score but using only $\mathrm{HI}$ items to derive an Individualism score is in line with recommendations and empirical evidence (Oyserman et al., 2002; Singelis et al., 1995; Schimmack et al., 2005).

\section{References}

Aiken, L.S., \& West, S.G. (1991). Multiple regression: Testing and interpreting interactions. Newbury Park, CA: Sage Publications. 
Bakermans-Kranenburg, M.J., \& van Ijzendoorn, M.H. (2009). The first 10,000 adult attachment interviews: Distributions of adult attachment representations in clinical and non-clinical groups. Attachment and Human Development, 11, 223-263. doi:10.1080/14616730902814762

Bartholomew, K., \& Horowitz, L.M. (1991). Attachment styles among young adults: A test of a four-category model. Journal of Personality and Social Psychology, 61, 226-244. doi:10.1037/0022-3514.61.2.22

Bowles, T. (2010). The Brief Attachment Adjective Checklist: A measure of the fourfold definition of the theory of attachment. Journal of Relationships Research, 1, 17-30. doi:10.1375/jrr.1.1.17

Brennan, K.A., Clark, C.L., \& Shaver, P.R. (1998). Self-report measurement of adult attachment: An integrative overview. In J.A. Simpson \& W.S. Rholes (Eds.), Attachment theory and close relationships (pp. 46-76). New York, NY: The Guilford Press.

Chan, R.C., Xu, T., Huang, J., Wang, Y., Zhao, Q., Shum, D.H., ... Potangaroa, R. (2012). Extending the utility of the Depression Anxiety Stress scale by examining its psychometric properties in Chinese settings. Psychiatry Research, 200, 879-883. doi:10.1016/j.psychres.2012.06.041

Cheng, S.T., \& Kwan, K.W. (2008). Attachment dimensions and contingencies of self-worth: The moderating role of culture. Personality and Individual Differences, 45, 509-514. doi:10.1016/j.paid.2008.06.003

Ditommaso, E., Brannen, C., \& Burgess, M. (2005). The universality of relationship characteristics: A cross-cultural comparison of different types of attachment and loneliness in Canadian and visiting Chinese students. Social Behavior and Personality, 33, 57-68. doi:10.2224/sbp.2005.33.1.57

Fraley, R., \& Davis, K.E. (1997). Attachment formation and transfer in young adults' close friendships and romantic relationships. Personal Relationships, 4, 131-144. doi:10.1111/j.1475-6811.1997.tb00135.x

Fraley, R., Heffernan, M.E., Vicary, A.M., \& Brumbaugh, C.C. (2011). The Experiences in Close Relationships - Relationship Structures questionnaire: A method for assessing attachment orientations across relationships. Psychological Assessment, 23, 615-625. doi:10.1037/a0022898

Frías, M.T., Shaver, P.R., \& Díaz-Loving, R. (2014). Individualism and collectivism as moderators of the association between attachment insecurities, coping, and social support. Journal of Social and Personal Relationships, 31, 3-31. doi:10.1177/0265407513484631

Friedman, M., Rholes, W., Simpson, J., Bond, M., Diaz-Loving, R., \& Chan, C. (2010). Attachment avoidance and the cultural fit hypothesis: A cross-cultural investigation. Personal Relationships, 17, 107-126. doi:10.1111/j.1475-6811.2010.01256.x

Friedman, M.D. (2006). Adult attachment and self-construal: A cross-cultural analysis. Dissertation Abstracts International: Section B: The Sciences and Engineering, 68(9-B).

George, C., Kaplan, N., \& Main, M. (1996). Adult attachment interview (3rd. ed.). Unpublished manuscript, University of California at Berkeley.

George, C., \& West, M. (2001). The development and validation of a new measure of adult attachment: The Adult Attachment Projective. Attachment \& Human Development, 3, 30-61.

Gillath, O., Sesko, A.K., Shaver, P.R., \& Chun, D.S. (2010). Attachment, authenticity, and honesty: Dispositional and experimentally induced security can reduce self- and other-deception.
Journal of Personality and Social Psychology, 98, 841-855. doi:10.1037/a0019206

Hamid, P.D., Simmonds, J.G., \& Bowles, T.V. (2009). Asian Australian acculturation and attitudes toward seeking professional psychological help. Australian Journal of Psychology, 61, 69-76. doi:10.1080/00049530701867839

Hazan, C., \& Shaver, P. (1987). Romantic love conceptualized as an attachment process. Journal of Personality and Social Psychology, 52, 511-524. doi:10.1037/0022-3514.52.3.511

Hazan, C., \& Shaver, P.R. (1994). Attachment as an organizational framework for research on close relationships. Psychological Inquiry, 5, 1-22. doi:10.2307/1449075

Heine, S.J., Lehman, D.R., Peng, K., \& Greenholtz, J. (2002). What's wrong with cross-cultural comparisons of subjective Likert scales?: The reference-group effect. Journal of Personality and Social Psychology, 82, 903-918. doi:10.1037/0022-3514.82.6.903

Henry, J.D., \& Crawford, J.R. (2005). The short-form version of the Depression Anxiety Stress Scales (DASS-21): Construct validity and normative data in a large non-clinical sample. British Journal of Clinical Psychology, 44, 227-239. doi:10.1348/014466505×29657

Ho, M.Y., Chen, S.X., Bond, M.H., Hui, C.M., Chan, C., \& Friedman, M. (2012). Linking adult attachment styles to relationship satisfaction in Hong Kong and the United States: The mediating role of personal and structural commitment. Journal of Happiness Studies, 13, 565-578. doi:10.1007/s10902-011-9279-1

Ho, M.Y., Zhang, H., Lin, D., Lu, A., Bond, M.H., Chan, C., \& Friedman, M. (2010). Saving graces: Impact of partner support and maternal attachment on partner attachments in an individualistic and a collectivist context. Asian Journal of Social Psychology, 13, 19-29. doi:10.1111/j.1467-839X.2010.01297.x

Hofstede, G. (1980). Culture's consequences. Beverly Hills, CA: Sage.

Horowitz, L.M., Rosenberg, S.E., \& Bartholomew, K. (1993). Interpersonal problems, attachment styles, and outcome in brief dynamic psychotherapy. Journal of Consulting and Clinical Psychology, 61, 549-560. doi:10.1037/0022-006X.61. 4.549

Hui, C.H. (1988). Measurement of individualismcollectivism. Journal of Research in Personality, 22, 17-36. doi:10.1016/0092-6566(88)90022-0

Iwamoto, D.K., \& Liu, W.M. (2010). The impact of racial identity, ethnic identity, Asian values, and race-related stress on Asian Americans and Asian international college students' psychological well-being. Journal of Counseling Psychology, 57, 79-91. doi:10.1037/a0017393

Karantzas, G.C., Feeney, J.A., \& Wilkinson, R.B. (2010). Is less more? Confirmatory factor analysis of the Attachment Style Questionnaires. Journal of Social and Personal Relationships, 27, 749-780. doi:10.1177/0265407510373756

Kim, Y., Carver, C.S., Deci, E.L., \& Kasser, T. (2008). Adult attachment and psychological well-being in cancer caregivers: The mediational role of spouses' motives for caregiving. Health Psychology, 27, S144-S154. doi:10.1037/0278-6133.27.2(Suppl.).S144

Kim, B.S.K., \& Omizo, M.M. (2003). Asian cultural values, attitudes toward seeking professional psychological help, and willingness to see a counselor. The Counseling Psychologist, 31, 343361. doi:10.1177/0011000003252268 
Lovibond, P.F., \& Lovibond, S.H. (1995). The structure of negative emotional states: Comparison of the Depression Anxiety Stress Scales (DASS) with the Beck Depression and Anxiety Inventories. Behaviour Research and Therapy, 33, 335-343. doi:10.1016/0005-7967(94)00075-U

Lu, A.-T., Zhang, J.-J., Michael, H.B., Zhang, X.-X., Michael, F., \& Chan, C. (2009). Cultural differences in the impacts of conflict and support on romantic partner attachment. Acta Psychologica Sinica, 41, 534-544. doi:https://doi.org/10.3724/ SP.J.1041.2009.00534

Mak, M.C.K., Bond, M.H., Simpson, J.A., \& Rholes, W. (2010). Adult attachment, perceived support, and depressive symptoms in Chinese and American cultures. Journal of Social and Clinical Psychology, 29, 144-165. doi:https://doi.org/10.1521/jscp. 2010.29.2.144

Malley-Morrison, K., You, H.S., \& Mills, R.B. (2000). Young adult attachment styles and perceptions of elder abuse: A crosscultural study. Journal of Cross-Cultural Gerontology, 15, 163184. doi:10.1023/a:1006748708812

Markus, H.R., \& Kitayama, S. (1991). Culture and the self: Implications for cognition, emotion, and motivation. Psychological Review, 98, 224-253. doi:10.1037/0033-295X.98.2.224

Mikulincer, M., Birnbaum, G., Woddis, D., \& Nachmias, O. (2000). Stress and accessibility of proximity-related thoughts: Exploring the normative and intraindividual components of attachment theory. Journal of Personality and Social Psychology, 78, 509-523. doi:10.1037/0022-3514.78.3.509

Mikulincer, M., \& Shaver, P.R. (2007). Attachment in adulthood: Structure, dynamics and change. New York, NY: The Guilford Press.

Norton, P.J. (2007). Depression Anxiety and Stress Scales (DASS-21): Psychometric analysis across four racial groups. Anxiety, Stress and Coping, 20, 253-265. doi:10.1080/ 10615800701309279

Oyserman, D., Coon, H.M., \& Kemmelmeier, M. (2002). Rethinking individualism and collectivism: Evaluation of theoretical assumptions and meta-analyses. Psychological Bulletin, 128, 3-72. doi:10.1037/0033-2909.128.1.3

Perissinotto, C.M., Stijacic Cenzer, I., \& Covinsky, K.E. (2012). Loneliness in older persons: A predictor of functional decline and death. Archives of Internal Medicine, 172, 1078-1084. doi:10.1001/archinternmed.2012.1993

Prigerson, H.G., Maciejewski, P.K., \& Rosenheck, R.A. (1999). The effects of marital dissolution and marital quality on health and health service use among women. Medical Care, 37, 858873. doi: $10.2307 / 3767417$

Sbarra, D.A., \& Emery, R.E. (2005). The emotional sequelae of nonmarital relationship dissolution: Analysis of change and intraindividual variability over time. Personal Relationships, 12, 213-232. doi:10.1111/j.1350-4126.2005.00112.x

Schimmack, U., Oishi, S., \& Diener, E. (2005). Individualism: A valid and important dimension of cultural differences between nations. Personality and Social Psychology Review, 9, 17-31. doi:https://doi.org/10.1207/ s15327957pspr0901_2

Schmitt, D.P., Alcalay, L., Allensworth, M., Allik, J., Ault, L., Austers, I., ... Zupan, A. (2004). Patterns and universals of adult romantic attachment across 62 cultural regions: Are models of self and of other pancultural constructs? Journal of CrossCultural Psychology, 35, 367-402. doi:https://doi.org/10.1177/ 0022022104266105
Schwartz, S.H. (2009). Draft users' manual: Proper use of the Schwarz Value Survey, version 14 January 2009 (compiled by R.F. Littrell). Auckland, New Zealand: Centre for Cross-Cultural Comparisons.

Shaver, P.R., Mikulincer, M., Sahdra, B.K., \& Gross, J.T. (2016). Attachment security as a foundation for kindness towards self and others. In K.W. Brown \& M.R. Leary (Eds.), The Oxford handbook of hypo-egoic phenomena (pp. 223-242). New York, NY: Oxford University Press.

Singelis, T.M., Triandis, H.C., Bhawuk, D.P.S., \& Gelfand, M.J. (1995). Horizontal and vertical dimensions of individualism and collectivism: A theoretical and measurement refinement. Cross-Cultural Research, 29, 240-275. doi:10.1177/ 106939719502900302

Taylor, S.E., Sherman, D.K., Kim, H.S., Jarcho, J., Takagi, K., \& Dunagan, M.S. (2004). Culture and social support: Who seeks it and why?. Journal of Personality and Social Psychology, 87, 354-362. doi:10.1037/0022-3514.87.3.354

Triandis, H.C., \& Gelfand, M.J. (1998). Converging measurement of horizontal and vertical individualism and collectivism. Journal of Personality and Social Psychology, 74, 118-128. doi:10.1037/0022-3514.74.1.118

van Ijzendoorn, M.H., \& Sagi-Schwartz, A. (2008). Cross-cultural patterns of attachment: Universal and contextual dimensions. In J. Cassidy \& P. Shaver (Eds.), Handbook of attachment: Theory, research and clinical applications (2nd ed., pp. 880-905). New York, NY: The Guilford Press.

Wang, C.D., \& Mallinckrodt, B.S. (2006). Differences between Taiwanese and U.S. cultural beliefs about ideal adult attachment. Journal of Counseling Psychology, 53, 192-204. doi:https:// doi.org/10.1037/0022-0167.53.2.192

Wang, C.D., \& Ratanasiripong, P. (2010). Adult attachment, cultural orientation, and psychosocial functioning of Chinese American college students. Cultural Diversity and Ethnic Minority Psychology, 16, 101-109. doi:https://doi.org/10.1037/ a0018634

Wei, M., Russell, D.W., Mallinckrodt, B., \& Zakalik, R.A. (2004). Cultural equivalence of adult attachment across four ethnic groups: Factor structure, structured means, and associations with negative mood. Journal of Counseling Psychology, 51, 408417. doi:10.1037/0022-0167.51.4.408

Wilkinson, R.B. (2010). Adolescent best friends as attachment figures: Implications for psychological health and adjustment. In J.C. Toller (Ed.), Friendships: Types, cultural, psychological and social aspects (pp. 1-37). Hauppauge, NY: Nova Science Publishers.

Wilkinson, R.B. (2011). Measuring attachment dimensions in adolescents: Development and validation of the Experiences in Close Relationships - Revised - General Short Form. Journal of Relationships Research, 2, 53-62. doi:10.1375/jrr. 2.1 .53

Wilkinson, R.B., \& Scherl, F.B. (2006). Psychological health, maternal attachment, and attachment style in breast and formula feeding mothers: A preliminary study. Journal of Reproductive and Infant Psychology, 24, 5-19. doi:10.1080/ 02646830500475153

You, H.S., \& Malley-Morrison, K. (2000). Young adult attachment styles and intimate relationships with close friends: A cross-cultural study of Koreans and Caucasian Americans. Journal of Cross-Cultural Psychology, 31, 528-534. doi:10.1177/0022022100031004006 